\title{
Deficiency in Aim2 affects viability and calcification of vascular smooth muscle cells from murine aortas and angiotensin-II induced aortic aneurysms
}

\author{
Markus Wortmann ${ }^{1}$, Muhammad Arshad ${ }^{1}$, Maani Hakimi ${ }^{1,2}$, Dittmar Böckler ${ }^{1}$ and Susanne Dihlmann ${ }^{1 *}$ (D)
}

\begin{abstract}
Background: Phenotypic transformation of vascular smooth muscle cells is a key element in vascular remodeling and aortic aneurysm growth. Previously, deletion of several inflammasome components decreased formation of aortic aneurysm (AA) in the Angiotensin II (Angll) -induced mouse model. We hypothesized that the inflammasome sensor Absent in melanoma 2 (Aim2) might affect the phenotype of vascular smooth muscle cells (VSMC), thereby reducing AA formation.
\end{abstract}

Methods: Aim2-/- mice and wild-type (WT) C57BI/6 J mice were used as an animal model. VSMC were isolated from 6 months old mice and grown in vitro. Young (passage 3-5) and senescent (passage 7-12) cells were analyzed in vitro for calcification in mineralization medium by Alizarin Red $\mathbf{S}$ staining. Expression of calcification and inflammatory markers were studied by real-time RT-PCR and Western blotting, release of cytokines was determined by ELISA. To induce AA, osmotic mini-pumps loaded with Angll (1500 ng/kg bodyweight/min) were implanted for 28 days in male mice at 6 months of age.

Results: Compared with VSMC from WT mice, VSMC isolated from Aim2-/- mice were larger, less viable, and underwent stronger calcification in mineralization medium, along with induction of Bmp4 and repression of Tnfsf11/ Rankl gene expression. In addition, Aim2 deficiency was associated with reduced inflammasome gene expression and release of Interleukin-6. Using the mouse model of Angll induced AA, Aim2 deficiency reduced AA incidence to 48.4\% (15/31) in Aim2-/- mice versus 76.5\% (13/17) in WT mice. In contrast to Aim2-/- mice, AA from WT mice expressed significantly increased levels of alpha-smooth muscle actin/Acta2, indicating tissue remodeling. Reduced cell proliferation in Aim2-/- mice was indicated by significantly increased p16ink4a/Cdkn2a expression in untreated and Angll-infused aortas, and by significantly lower amounts of proliferating (Ki67 positive) VSMC in Angll-infused Aim2-/- mice.

Conclusions: Our results suggest a role for Aim2 in regulating VSMC proliferation and transition to an osteoblastlike or osteoclast-like phenotype, thereby modulating the response of VSMC in aortic remodeling and AA formation.

Keywords: VSMC, Phenotype transition, Inflammasome, Senescence, Proliferation, Aortic aneurysm

\footnotetext{
* Correspondence: susanne.dihlmann@med.uni-heidelberg.de

'Department of Vascular and Endovascular Surgery, University Hospital Heidelberg, University of Heidelberg, Im Neuenheimer Feld 110, 69120 Heidelberg, Germany

Full list of author information is available at the end of the article
}

(c) The Author(s). 2020 Open Access This article is licensed under a Creative Commons Attribution 4.0 International License, which permits use, sharing, adaptation, distribution and reproduction in any medium or format, as long as you give appropriate credit to the original author(s) and the source, provide a link to the Creative Commons licence, and indicate if changes were made. The images or other third party material in this article are included in the article's Creative Commons licence, unless indicated otherwise in a credit line to the material. If material is not included in the article's Creative Commons licence and your intended use is not permitted by statutory regulation or exceeds the permitted use, you will need to obtain permission directly from the copyright holder. To view a copy of this licence, visit http://creativecommons.org/licenses/by/4.0/. 


\section{Background}

Phenotype transformation of vascular smooth muscle cells (VSMC) is considered a driving force of many vascular diseases, including aortic aneurysms (Bennett et al. 2016; Hortells et al. 2018; Riches et al. 2018). Human abdominal aortic aneurysm (AAA) is an age-related disease, defined by dilation of the aorta by more than half of the original diameter. During aneurysm growth, the aortic wall is extensively remodeled and weakened, thereby increasing the risk of rupture, which results in massive, and often fatal internal bleeding (Reimerink et al. 2013; Sampson et al. 2014). Current clinical interventions are associated with significant morbidity and mortality, and sometimes surgery is not possible at all. Therefore, there is an unmet clinical need for development of a conservative medical treatment to limit or prevent progression of small AAAs by specifically targeting the vascular remodeling processes.

The sequential pathogenesis and detailed biological mechanisms underlying AAA formation are incompletely understood. Remodeling of the aortic wall is accompanied by invasion of inflammatory and immune cells, extensive alterations in the extracellular matrix composition and considerable changes of VSMC phenotype (Ailawadi et al. 2009; Golledge 2019; Petsophonsakul et al. 2019). In the healthy aorta, most VSMC display a quiescent contractile phenotype, defined by expression of contractile proteins such as alphasmooth muscle actin ( $\alpha$ SMA) and smooth muscle myosin II, which allows them to maintain vascular tone. In response to physical or biochemical stress factors that accumulate with ageing, VSMC have the ability to switch to synthetic phenotypes. Synthetic VSMC are characterized by a decreased expression of contractile proteins and increased expression of extracellular matrix degrading enzymes, inflammatory cytokines and/or calcification-promoting genes (Owens et al. 2004). In addition, multipotent vascular stem cells, residing in the vessel wall appear to differentiate into VSMC in response to injury and adapt myofibroblast-like, macrophagelike, or osteoblast-like phenotypes (Tang et al. 2012). Today, VSMC phenotypic switching and calcification are considered key in AAA formation (Petsophonsakul et al. 2019; Riches et al. 2018) and the phenotypic modulation has been shown to be an early event in the aorta before aneurysm growth (Ailawadi et al. 2009).

Using animal and in vitro cell culture models, a number of cellular signaling pathways have been identified, which regulate VSMC transition in aortic aneurysm formation (reviewed in (Petsophonsakul et al. 2019) and (Golledge 2019)):

(1) BMP- and Wnt/ $\beta$-Catenin-Signaling have been implicated in regulating osteochondrogenic differentiation of VSMC under calcifying conditions and to promote angiotensin II (AngII) induced aortic aneurysm (AA) (Freise et al. 2016; Krishna et al. 2017; Towler 2017). (2)
Components of the inflammasomes, which mediate Caspase- 1 dependent activation of interleukin $1 \beta$ (IL-1 $\beta$ ) and subsequent inflammatory cascade, have been shown to contribute to VSMC transformation and aortic aneurysms (Johnston et al. 2013, 2014). NLR family pyrin domain containing 3 (NLRP3) is required for VSMC phenotypic transformation and calcification (Ren et al. 2017; Sun et al. 2017; Wen et al. 2013). In addition, genomic inactivation of the inflammasome components Nlrp3, Casp1 (Caspase-1) and Apc (Apoptosis-associated speck-like protein containing a caspase recruitment domain) reduced the development of AngII-induced aortic aneurysm by inhibiting IL-1 $\beta$ release from bone marrow derived macrophages (Usui et al. 2015).

Absent in melanoma 2 (AIM2) is another well-described inflammasome component, that has recently been implicated to play a role in human AAA formation (Dihlmann et al. 2014; Hakimi et al. 2014; Wortmann et al. 2019b; Wu et al. 2016) and other inflammatory diseases (Sharma et al. 2019). In response to cytoplasmic double stranded (ds) DNA, AIM2 activates an inflammasome in macrophages (Fernandes-Alnemri et al. 2009; Hornung et al. 2009). Its role in other vascular cell types is less well defined, although we could recently show that human VSMC derived from AAA-patients respond to necrotic cell debris with an induction of AIM2 (Wortmann et al. 2019a). Given this observation and the above-mentioned association of inflammasome activity with AAA and calcification, we aimed to further investigate the role of AIM2 in murine VSMC and AA formation. We hypothesized that the VSMC phenotype, particularly calcification in response to ageing and/or AngII, might be altered by AIM2. To test this hypothesis, we used VSMC cultures isolated from Aim2-/(C57Bl/6 J background) and WT (C57Bl/6 J) mice. Furthermore, we aimed to test whether an Aim2 knockout protects from AA development in the well-established murine AngII-induced model, whereby AA formation is triggered by continuous subcutaneous application of AngII to mice. To further identify the molecular basis for these effects, VSCM cultures, isolated from AngII-induced mice were also analyzed for phenotypic changes. The findings obtained in this study provide insight into the pathophysiology of AA, suggesting that AIM2 may be added to the therapeutic targets for preventing AA progression.

\section{Methods}

\section{Animal models}

All experiments in this study were performed in accordance with federal law for animal protection and approved by the regional council of Baden-Wuerttemberg (Regierungspraesidium Karlsruhe). Aim2-/- mice (B6.129P2Aim $\left.2^{G t(C S G 445) B y g} / \mathrm{J}\right)$ and wild-type (WT) C57Bl/6 J mice $\left(\mathrm{JAX}^{\mathrm{ms}} \mathrm{C} 57 \mathrm{BL} / 6 \mathrm{~J}\right)$, used as a control, were purchased from Charles River (Sulzfeld, Germany). All mice used in this 
study had a C57Bl/6 J genetic background. Male mice at 6 months of age were chosen for our experiments to model the epidemiological background in humans, where AA is associated with increased age and male sex (Forsdahl et al. 2009; Hannawa et al. 2009). Mice were kept in a pathogen-free animal facility (IBF Heidelberg) with standard rodent food and tap water ad libitum. To induce AA, osmotic mini-pumps (Model 2004, Alzet Scientific products, Cupertino, CA) loaded with AngII (1500 ng/kg bodyweight $/ \mathrm{min}$ ) were implanted in the dorsal subcutaneous space for 28 days in male mice at 6 months of age. During surgery, for performing regular ultrasound examinations, and at the end of the 4-week experiment, mice were anesthetized with isoflurane.

\section{Assessment of AA formation}

Maximum aortic diameter was determined on a weekly basis by ultrasound. In absence of an aneurysm, maximum aortic diameter was measured at the entry into the abdominal cavity at the level of the diaphragm. Dilation of the aortic diameter to $>1.5 \mathrm{~mm}$ was defined as an aneurysm. In this case the maximum diameter of the aortic aneurysm was measured. In addition, aortic aneurysms were histologically confirmed post-mortem using serial sections of formalin-fixed paraffin-embedded aortas.

\section{VSMC cell culture}

VSMC were isolated from aortas of 6 months old male mice, infused for 28 days with AngII, or from agematched control animals. Aortas were cut up into small pieces and digested with $400 \mathrm{U} / \mathrm{ml}$ collagenase type II (Worthington, Biochemical Corporation, Lakewood, USA) for $1-2 \mathrm{~h}$ at $37^{\circ} \mathrm{C}$ with shaking. Isolated cells were washed with PBS and expanded in 6-well plates containing Smooth Muscle Cell Growth Medium 2 (PromoCell, Heidelberg, Germany), supplemented with antibiotics (100 U/ml penicillin/streptomycin and $5 \mu \mathrm{g} / \mathrm{ml}$ amphotericin B) in a humidified atmosphere of $5 \% \mathrm{CO}_{2}$. Cells were pooled from 2 to 3 animals. The media was replaced every 3 days. Subcultures were obtained by using 0.05\% Trypsin/EDTA (Life Technologies, Gibco, Paisley, UK) and cells were split 1:2 when reaching 70-90\% confluence. Identification of vascular smooth muscle cells was performed by visual inspection of morphology and growth in hills and valleys, and the cells were analyzed at different passages for expression of alpha smooth muscle actin. Cells were considered young for the first 3-5 passages and used for experiments with proliferating cells. To obtain replicative senescent cells, VSMC were split regularly in Smooth Muscle Cell Growth Medium 2 until they stopped growing for more than 2 weeks.

\section{Analysis of the number of passages}

A subset of each VSMC culture was grown in six-well plates, and cells were split 1:2 when reaching 90-100\% confluence. Senescence was defined as complete growth cessation for more than 2 weeks.

\section{Cell proliferation / viability assay}

VSMC were seeded at a density of 1000 cells per well in a 96well plate in triplicates. Serum starvation was performed over night by reducing the medium supplement to $10 \%$ of the amount that was required for regular growth (Smooth Muscle Cell Growth Medium 2; PromoCell, Heidelberg, Germany). After $24 \mathrm{~h}$, the starvation medium was replaced by full medium $(100 \mu \mathrm{l}$ per well) and cells were grown for an additional $0 \mathrm{~h}, 24 \mathrm{~h}, 48 \mathrm{~h}, 72$ $\mathrm{h}$ and $96 \mathrm{~h}$. At the different time points, $10 \mu \mathrm{l}$ per well of WST-1 reagent (Roche Diagnostics $\mathrm{GmbH}$, Mannheim Germany) was added to the cells for $30 \mathrm{~min}$. in a humidified atmosphere at $37^{\circ} \mathrm{C}$ and $5 \% \mathrm{CO}_{2}$. Absorbance of the samples was measured against a background control using a microplate reader at a wavelength of $450 \mathrm{~nm}$ and a reference wavelength of $620 \mathrm{~nm}$.

\section{Induction and quantification of VSMC in vitro calcification} Cells were shifted to Osteoblast Mineralization Medium (PromoCell, Heidelberg, Germany) for 14 or 21 days, with medium change every 3 days to induce calcification. VSMC were washed three times with PBS and calcium deposition was visualized and quantified by Alizarin Red $S$ (ARS staining quantification assay, Sciencell Research Laboratories, San Diego, CA, USA) as recommended by the manufacturer. Briefly, cells were fixed in $4 \%$ formaldehyde for $15 \mathrm{~min}$. at room temperature and washed three times with distilled $\mathrm{H}_{2} \mathrm{O}$. One $\mathrm{ml}$ of $40 \mathrm{mM}$ ARS was added per well and incubated at room temperature for $30 \mathrm{~min}$. With shaking. After washing of the cells five times with distilled $\mathrm{H}_{2} \mathrm{O}$, images were taken using a microscope. Plates were stored at $-20{ }^{\circ} \mathrm{C}$ prior to dye extraction. For quantification, $800 \mu \mathrm{l}$ of $10 \%$ acetic acid was added to each well of the 6-well plate for $30 \mathrm{~min}$. Cells were collected using a cell scraper and transferred to a microcentrifuge tube. After vortexing for $30 \mathrm{~s}$, samples were heated at $85^{\circ} \mathrm{C}$ for $10 \mathrm{~min}$. Samples were incubated on ice for $5 \mathrm{~min}$ and centrifuged at $20000 \mathrm{~g}$ for 15 min. Supernatants were transferred to a new tube and $200 \mu \mathrm{l}$ of $10 \%$ ammonium hydroxide was added. Absorbance of the samples was read at $405 \mathrm{~nm}$ with a plate reader and plotted against an ARS standard curve to determine the concentration.

\section{RNA extraction and quantitative real-time polymerase chain reaction (qRT-PCR)}

Extraction of total RNA, using Qiagen RNase Mini Kit from cells, and real-time PCR (with an ABI StepOnePlus reader) 
was performed as described previously (Wu et al. 2015). Primer sequences are listed in supplementary table 1. Relative expression was determined from cycle thresholds $\left(C_{T}\right)$ by using individual standard amplification curves of each transcript relative to the corresponding mean expression of three reference transcripts (mouse genes: Gapdh, B2m, Actb).

\section{Immunoblot analysis}

Cells were harvested in cell lysis buffer and homogenized by ultrasound as described previously (Wu et al. 2016). Twenty $\mu \mathrm{g}$ of each lysate were separated by SDS-PAGE and blotted onto nitrocellulose. Detection of proteins was performed over night with primary antibodies diluted in appropriate buffers as recommended by the manufacturers. Anti-CDKN2A/p16ink4a (EPR20418, No. ab211542; 1:2000) was purchased from Abcam. Mousespecific antibodies against $\alpha$-smooth muscle actin (D4K9N, No. 19245; 1:1000), Phospho-Histone H2A.X (Ser139, No. 9718; 1:1000), Phospho-NF-kB p65 (Ser536, No. 3033; 1:1000) and GAPDH (14C110; No. 2118; 1: 1000) were all purchased from Cell Signaling Technology, Danvas, MA, USA. Anti-rabbit IgG HRP-linked secondary antibody (No. 7076, Cell Signaling Technologies; 1:2000) and Western Bright ECL (Advansta, Menlo Park, CA, USA) were used for signal detection by chemoluminescence.

\section{Quantification of cytokine release into cell supernatant}

Supernatants derived from cells were analyzed for concentrations of active cytokines and chemokines according to the recommendations of the manufacturers. For analysis of cleaved IL-1 $\beta$ (p17) the Duo-Set ELISA Development system for murine IL-1 $\beta$ (R\&D Systems Europe, Abington, UK) was used. ELISA kits for analysis of murine IL-6 and sRANKL in the supernatants were purchased from Peprotech, London, UK.

\section{Histology and immunohistochemistry}

Mouse aortas were fixed in $4 \%$ formalin, embedded in paraffin and $2-5 \mu \mathrm{m}$ serial sections were cut using a microtome. Sections were stained with haematoxilin (HE), Sirius Red, or Elastica van Gieson (EVG) according to standard procedures. Detailed protocols are available upon request.

For immunohistochemical analysis, sections were dried overnight, deparaffinised and incubated overnight with specific antibodies detecting alpha-smooth-muscle actin (D4K9N, No. 19245, Cell Signaling Technology), p16ink4a (EPR20418, Abcam ab211542), Ki67 (No. 12202, Cell Signaling Technology) or CD45 (MAB114, Biotechne, R\&D Systems). R.T.U. biotinylated anti-rabbit IgG (BP-9100, Vector Laboratories, Burlingame, CA, USA) and R.T.U Vectastain Elite ABC reagent, Peroxidase (R.T.U. Vectastain Kit; PK-7100, Vector Laboratories) were used for detection, as described by the manufacturer. Development was performed with ImmPAct AEC reagent (SK-4205, Vector Laboratories). Sections were counterstained with Mayer's hemalum solution (1:10). Slides were scanned for digital histology with Aperio ImageScope v12.2.2.5015.

\section{Statistics}

GraphPad Prism 8 software (GraphPad, San Diego, CA, USA) was used to perform statistical analyses. Categorical variables (i.e. AA incidence in different mouse genotypes) were analyzed as 2 by 2 contingency tables by Fisher's exact test. D'Agostino \& Pearson test was used to test the data sets (mRNA expression in Figs. 1 and 2) for normal distribution. Statistical significance was tested using one-way analysis of variance (ANOVA) or Student's t-test as indicated in the figures. The numbers of individuals, cell cultures, independent experiments and other variables used for each test, are indicated in the figure legends. Data are expressed as mean \pm SEM or \pm $\mathrm{SD}$ as indicated in the figure legends. $P$-values of $<0.05$ were considered statistically significant.

\section{Results}

An Aim2 knockout affects the morphology, replicative potential and senescence of murine VSMC

We first investigated effects of Aim2 deficiency on native VSMC isolated from 6 month (28.4-31.4 weeks) old animals. Examination of early cultures (passage $1-3)$ by light microscopy demonstrated that VSMC derived from Aim2-/- mice reproducibly formed large rhomboidal cells with star-shaped filaments (Fig. 1a), as described for the synthetic phenotype (reviewed in (Petsophonsakul et al. 2019)). In contrast, VSMC derived from WT mice were spindleshaped and grew densely packed in typical hills and valleys as described for the contractile phenotype (Petsophonsakul et al. 2019). Furthermore, VSMC derived from Aim2-/- mice grew slowly with an average doubling time of 3-4 days and reached senescence after $8.3+/-2.3$ passages (1:2 splitting), whereas VSMC derived from WT mice stopped growing after $11.3+/-1.1$ passages (Fig. 1b). Accordingly, the viability of VSMC from Aim2-/- mice was significantly reduced (Fig. 1c) and expression of the senescence marker $C d k n 2 a$ (p16ink4a) was significantly higher in early passage (proliferating) and senescent Aim2-/- VSMC than in corresponding WT VSMC (Fig. 1d (-OM)). In line with a synthetic phenotype, expression of Acta $2 / \alpha \mathrm{SMA}$ was significantly lower in proliferating Aim2-/- VSMC compared with WT VSMC and was further reduced in both genotypes, when the cells reached replicative senescence (Fig. 1e, $(-\mathrm{OM}))$. 

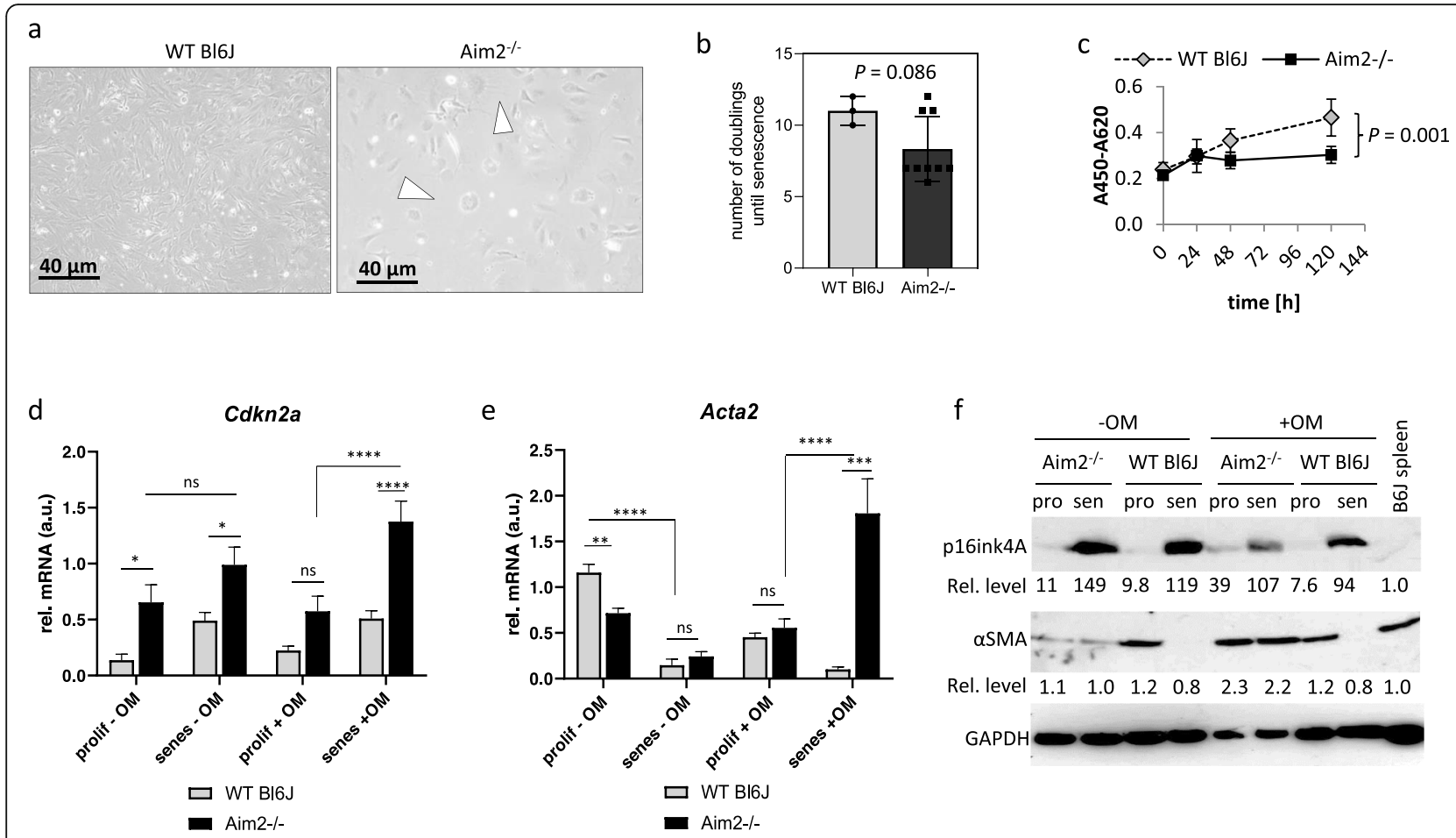

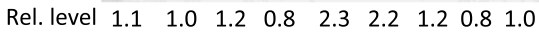

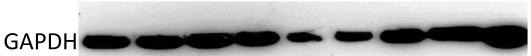

Fig. 1 Aim2 knockout affects the morphology, replicative potential and senescence of murine VSMC. VSMC were isolated from WT and Aim2 ${ }^{-/-}$ mice and pooled. Each pool contained VSMC of 3 animals. a VSMC derived from Aim2-/- mice are larger, rounded and contain big vacuoles. The picture shows representative cultures of passage 3 from $n=6$ (Aim2-l-) and $n=7$ (WT) VSMC pools. b VSMC derived from Aim2-l- mice ( $n=9$ pools) undergo faster replicative senescence than WT VSMC ( $n=3$ pools). $\mathbf{c}$ Viability of VSMC was determined by WST1-proliferation assay after proliferation of the cells for $24,48,72$ and $96 \mathrm{~h}$ in normal growth medium. d-e Analysis of mRNA expression of the senescence marker Cdkn2al p16 (d) and Acta2 (e) was determined by real-time RT-PCR from VSMC grown in normal growth medium or in mineralization medium (OM). Data show the mean and SEM derived from 3 pools of proliferating (passage 3-4) and senescent (passage 7-12) VSMC. Senescence was defined as no proliferation for $>2$ weeks. Data were tested by one-way ANOVA. ns: not significant, ${ }^{*}: P<0.05 ;{ }^{* *} P<0.01$; ${ }^{* * *}$ : $P<0.0001$. f Western blot showing expression of p16ink4A and a-SMA in VSMC pools (derived from $n=2-3$ animals per pool) of Aim2-/- versus WT mice. Numbers represent the relative protein level normalized to GAPDH. Expression level in the spleen of WT mice was set as 1.0

Aim2 knockout promotes osteoblastogenic differentiation of murine VSMC in vitro

Because VSMC phenotypic switching and calcification were shown to be a key event in aneurysm formation (Petsophonsakul et al. 2019), we next asked whether AIM2 is involved in VSMC calcification. To address this query, proliferating and senescent VSMC were shifted to mineralization medium for 2 weeks in vitro. A commercially available osteoblast mineralization medium was chosen for this experiment, because it enables mineralization of existing osteoblast-like precursors. Calcification of VSMC in this culture medium was tested in preliminary experiments with murine VSMC (supplementary figure S1). Staining with Alizarin Red S demonstrated a significantly increased calcification level in proliferating VSMC from Aim2-/- mice after shifting to mineralization medium (Fig. 2a, b).

Again, gene expression of the senescence marker $C d k n 2 A / p 16$ was significantly higher in Aim2-/- VSMC, compared with WT VSMC, grown for 2 weeks in mineralization medium (Fig. 1d, (+OM)). However, there was no further increase compared with VSMC grown in normal growth medium. Consistent with VSMC phenotype transition, gene expression of Acta2 was downregulated in WT VSMC grown in mineralization medium, when the cells reached senescence (Fig. 1e, f). Interestingly, both Acta 2 mRNA and corresponding aSMA protein levels were strongly upregulated in senescent Aim2 $-/-$ VSMC, grown in mineralization medium (Fig. 1e and $\mathrm{f},(+\mathrm{OM}))$.

To further understand the mechanism underlying the increased calcification of Aim2-/- VSMC, we investigated expression of a set of genes involved in osteochondrogenic differentiation. A markedly increased expression of Bmp4 was observed in Aim2-/VSMC (Fig. 2c), whereas expression of the osteoclast differentiation factor Tnfsf11/Rankl was completely repressed (Fig. 2d). In line with this, expression of Runx2, a transcription factor known to regulate the Rankl promoter was also significantly lower in Aim2 -/- VSMC, particularly, when the cells reached 


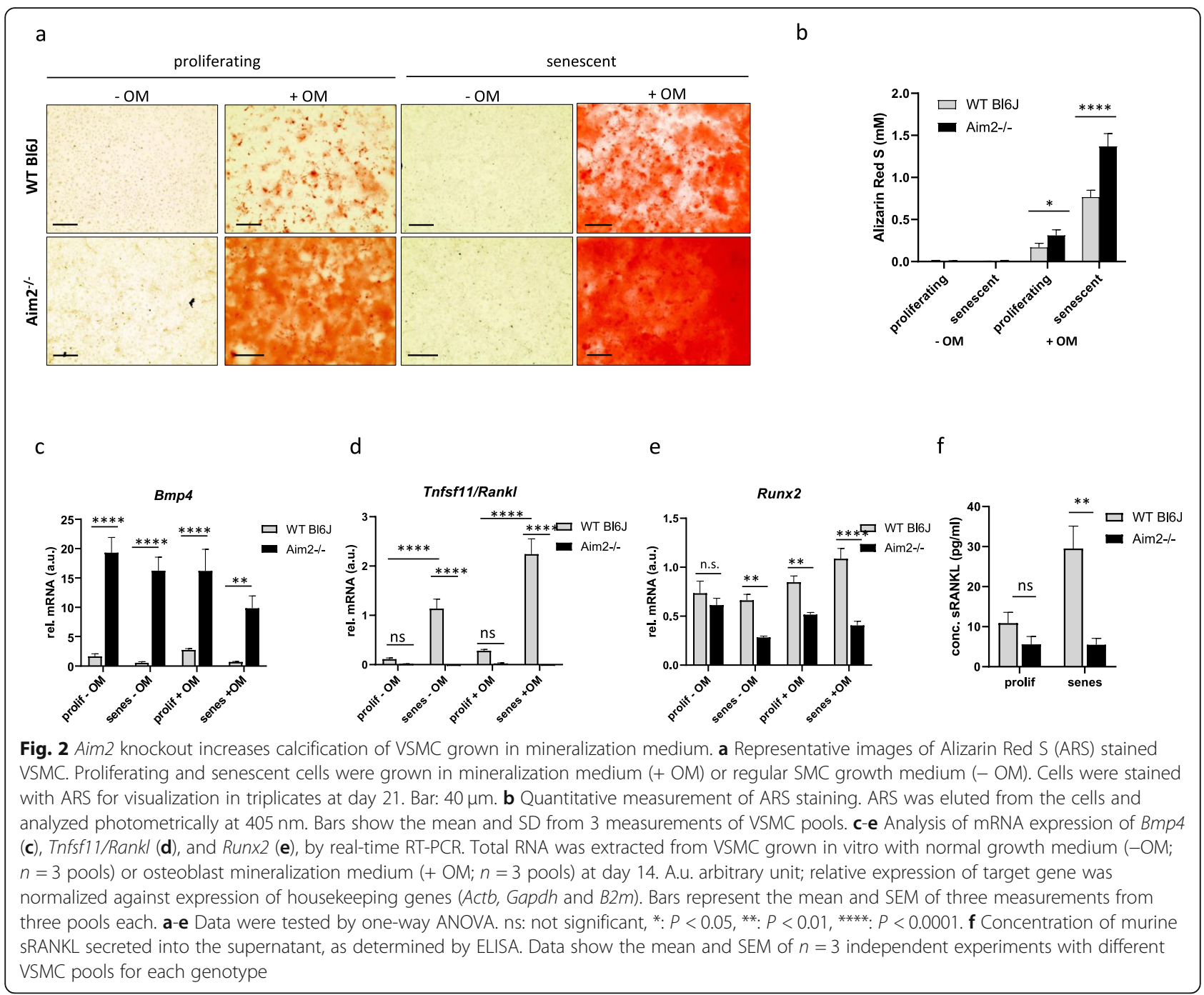

replicative senescence (Fig. 2e). The expression differences were observed before and after shifting the cells to mineralization medium, indicating that this was an inherent feature of the different genotypes and was not induced by external factors. Tnfsf11/Rankl mRNA levels were further increased in WT VSMC reaching senescence but remained absent in Aim2-/- VSMC (Fig. 2d). Accordingly, secretion of sRANKL was significantly reduced in Aim2-/- VSMC compared with WT VSMC (Fig. 2f). Expression of the osteoblast marker Bmp2 was particularly reduced in Aim2-/VSMC grown in normal growth medium, whereas this difference disappeared when the cells were shifted to mineralization medium. (Supplementary figure S2a). The mRNA expression of other genes involved in osteogenic differentiation was not associated with the genotype. Col1A1, Col2A1, Mmp9 and Sox9 expression displayed great variations between individual VSMC cell pools, resulting in marginal or not significant differences between WT and Aim2-/VSMC (Supplementary figure S2b-e).

\section{Aim2 deficiency is associated with a reduced inflammatory response of VSMC}

Because of its role as an inflammasome sensor in macrophages and other cell types, we next investigated whether inflammasome gene expression was affected by AIM2 in VSCM in vitro (Fig. 3 and supplementary figure S3). As expected, Aim 2 mRNA was not detectable in Aim2-/VSMC (Fig. 3a). In addition, mRNA expressions of the inflammasome components Nlrp3 and $I l 1 b$ were significantly lower in Aim2-/- VSMC compared with WT VSMC in both, normal growth medium and after shifting the cells to mineralization medium for 2 weeks (Fig. 3b, c). Release of mature IL- $1 \beta$ from VSMC did not differ between the genotypes (Fig. 3d). In contrast, release of IL-6 was significantly lower in Aim2-/- VSMC (Fig. 3e). In line with the lower Nlrp3 and $I l 1 b$ transcription levels, 


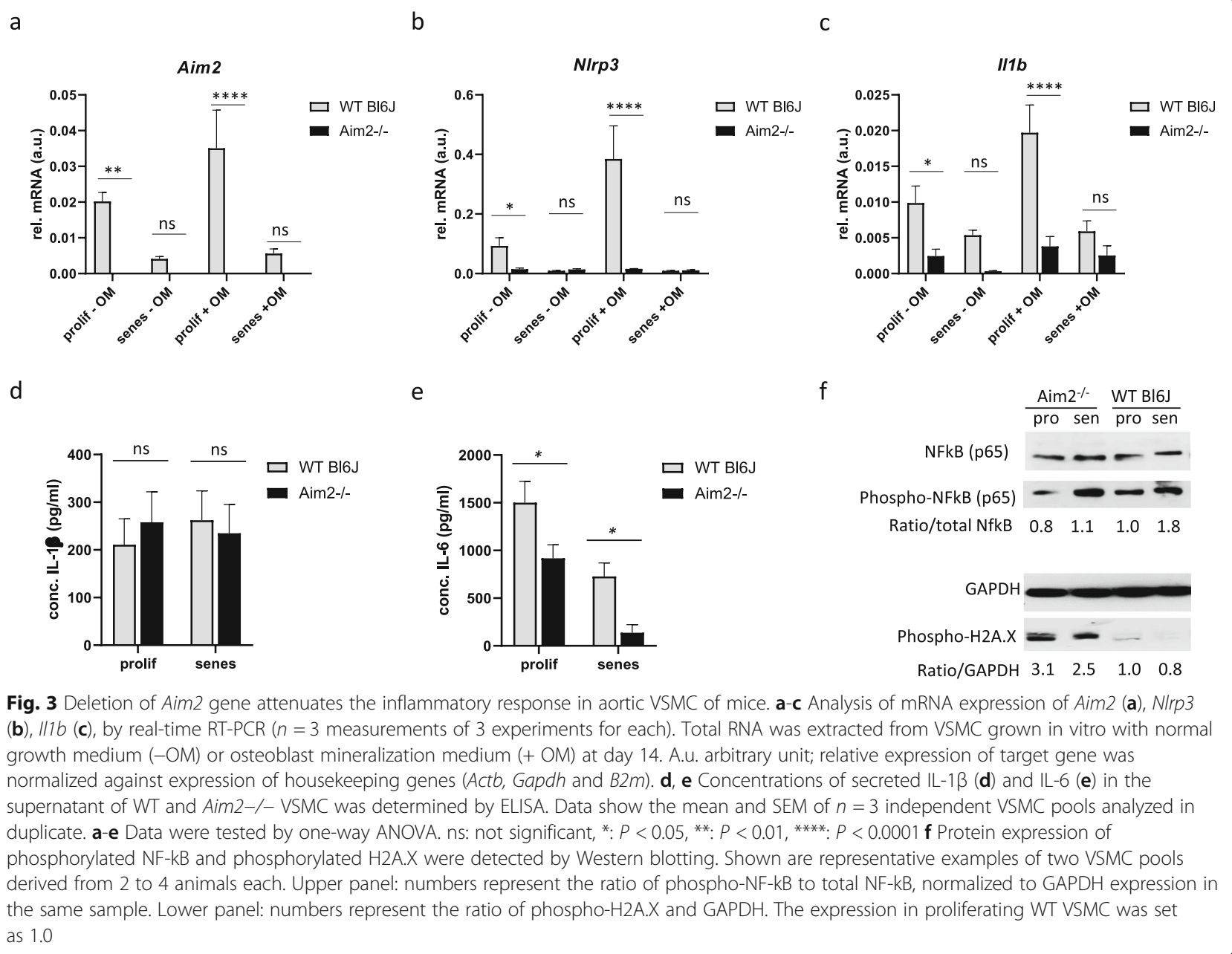

expression of the inflammatory transcription factor phospho-NF-kB (Ser536) was reduced in Aim2-/- VSMC compared with WT VSMC, despite an increased DNA damage in these cells, as indicated by phosphorylation of Histone H2A.X at Ser139 (Fig. 3f). Together these data suggest a reduced inflammatory response in Aim2-/VSMC.

\section{Aim2 deficiency reduces AA incidence and affects aortic remodeling in Angll-induced aortic aneurysm}

Considering the impact of Aim2 deficiency on VSMC calcification and inflammatory response, we hypothesized that Aim 2 knockout might reduce AA formation in vivo. To investigate this hypothesis, we infused Aim2-/- and WT mice with AngII for 4 weeks. Four out of 31 (13\%) Aim2-/- mice and four out of 17 (23\%) WT mice died before the $28 \mathrm{~d}$ infusion period following aortic rupture. Consistent with previous reports from AngII-infused Apoe -/- mice (Daugherty et al. 2000; Usui et al. 2015), aortic aneurysms were induced in 76\% (13/17) of WT mice. In contrast, only 48\% (15/31) of Aim2-/- mice developed an
AA (Fig. 4a). Although the difference in AA incidence was not statistically significant (Fisher's exact test, $P=0.055$ ), we aimed to elucidate the aortas in more detail. Apparently, all aneurysms in WT mice were located either in the suprarenal or thoracic aorta. In contrast, in Aim2-deficient mice, all aneurysms were located in the infrarenal aorta (Fig. 4b). The reason for this difference is unclear and was not further analyzed.

Plasma levels of IL- $1 \beta$ and IL- 6 did not significantly differ between WT and Aim2-/- mice after 28 days of AngII infusion (supplementary figure S4). Moreover, mRNA expression levels of the inflammatory cytokines $I l 1 b, I l 6, I l 18$ and $M c p 1$ were similar in aortas of AngII-infused WT and Aim2-/- mice (supplementary figure S4c), indicating that there was no difference in inflammation at the end of the experiments. In contrast, mRNA expression of the senescence marker $C d k n 2 A / p 16 i n k 4 A$ was increased in Aim2 -/- aortas from both, untreated and AngII infused mice (Fig. 4c), whereas Acta2 expression was only increased in aortas form AngII infused WT mice (Fig. 4d). Increased expression of p16ink4A protein was also detected by 


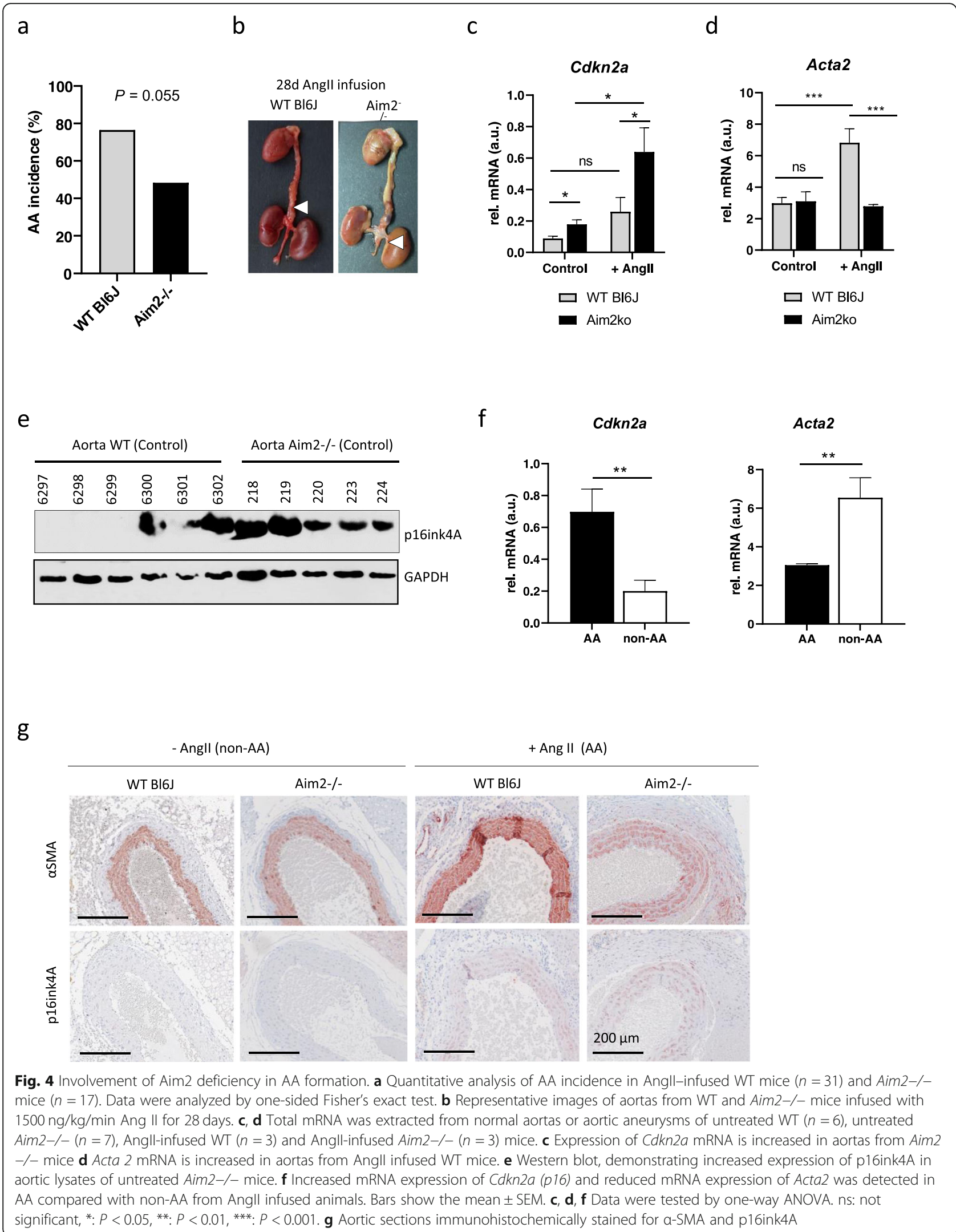




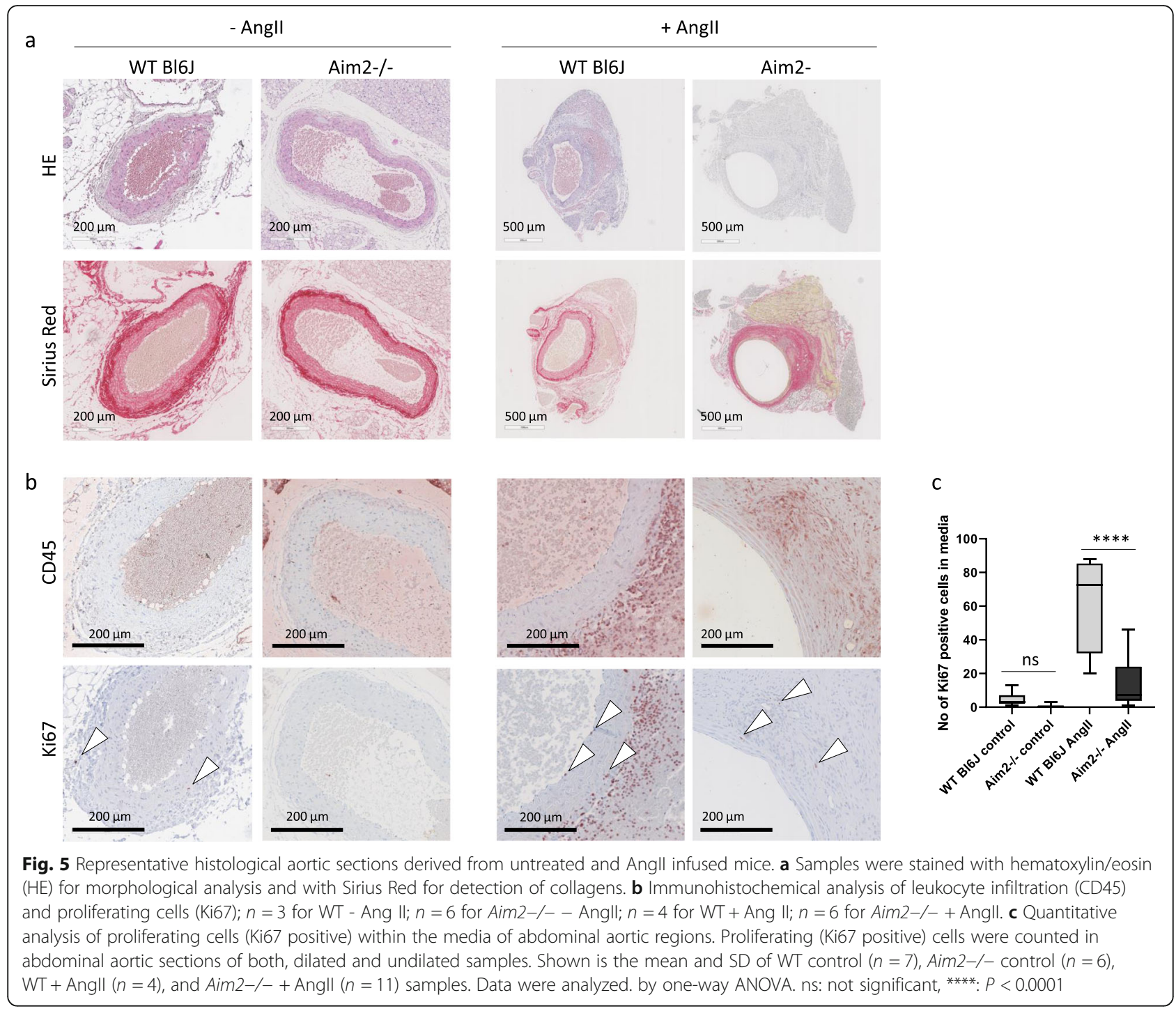

Western blotting of aortas derived from non-infused (control) Aim2-/- mice (Fig. 4e). When AA samples were compared with normal aortas, $C d k n 2 A / p 16 i n k 4 A$ was elevated and Acta2 was decreased in either genotype (Fig. 4f). Accordingly, protein expression of p16ink4A was significantly increased in AA samples, compared with normal aortas (Supplementary figure S5a, b).

To investigate the role of VSMC in AA formation, we performed immunohistochemical analysis and found that p16ink4A was particularly expressed in VSMC ( $\alpha$ SMA-positive cells) of AA samples and adjacent adventitial regions of WT and Aim2-/- mice, respectively, whereas it was completely absent in VSMC of healthy aortas (Fig. 4g). In line with the mRNA data, expression of $\alpha$ SMA was stronger in AA samples of AngII infused WT mice (Fig. 4g). The composition of AAs, as determined by hematoxylin and Sirius Red staining, did not differ significantly between the two genotypes (Fig. 5a).
In addition, AAs of both genotypes were equally infiltrated with leukocytes, as indicated by CD45 expression (Fig. 5b). In contrast, the number of proliferating cells (Ki67 positive) was significantly lower in aortic medias from control and AngII infused Aim2-/- mice, compared with WT mice (Fig. 5b and c), which is in good agreement with the in vitro data, showing a lower viability and growth rate of Aim2-/- VSMC.

\section{Aim2 deficiency and inflammasome activation in VSMC derived from Angll-infused mice}

To determine whether the VSMC phenotype was persistently affected by the 28-day-AngII-infusion, aortic VSMC were isolated from AngII-infused animals and grown in vitro. Similar to control animals, VSMC derived from AngII treated Aim2-/- animals were larger and grew more slowly than VSMC derived from AngII treated WT animals (supplementary Figure S5c). In 
contrast to VSMC from untreated mice, mRNA expression of the innate immunity genes Nlrp3 and Illb did not differ between Aim2 deficient and WT VSMC of AngII infused mice. Moreover, mRNA expression of Casp1, Asc/Pycard, and Il18 was similar in both genotypes (supplementary Figure S5d).

\section{Discussion}

The primary novel finding of this study is that AIM2 is functionally involved in phenotype transition of VSMC. Aim2 deficiency resulted in reduced proliferation, accelerated senescence and an early shift to a synthetic phenotype of murine aortic VSMC. This was accompanied by increased calcification but reduced inflammatory response of Aim2-/- VSMC. In line with the reduced inflammation, the AA incidence was lower in Aim2 knockout mice in the in vivo model of AngII-infused mice. At first sight, the reduced in vitro proliferation rate in combination with a synthetic phenotype of Aim2 deficient VSMC appears to contradict previous reports, which showed that proliferating activity is higher in synthetic than in contractile VSMC. However, one should bear in mind that the cells have been growing in vivo for 6 months before they were isolated for in vitro culturing. Potentially, Aim 2 deficient VSMC displayed faster proliferation in vivo and are therefore already closer to replicative senescence than their WT counterparts. Although we have not determined the in vivo proliferation rate, this might explain the higher p16ink4A expression along with earlier senescence that was observed here reproducibly in all Aim2-/- VSMC cultures analyzed. Moreover, in contrast to WT VSMC, Acta2/ $/$ SMA expression was not reduced in Aim2 deficient VSMC, when the cells reached senescence. Together with the reduced inflammatory activity of Aim2-/- VSMC, this agrees with a protective mechanism of Aim 2 deficiency in aortic VSMC.

The mechanism by which Aim 2 deficiency results in accelerated senescence and calcification of VSMC is currently unknown. AIM2 is a dsDNA sensor that is mainly activated in monocytes and macrophages by cytoplasmic DNA, derived from pathogens or neighboring necrotic cells (Briard et al. 2020). In addition, there is accumulating evidence for AIM2 to be involved in sustaining mitochondrial function by detecting mitochondrial DNA (mtDNA) in various human diseases, including cancer and diabetes type 2 (Bae et al. 2019; Qi et al. 2020), as well as in detecting virusinduced oxidized DNA (Moriyama et al. 2020). In neurodevelopment, AIM2 was recently shown to be involved in surveillance of DNA damage of neurons (Lammert et al. 2020). Finally, mitochondrial ROS (reactive oxygen species) overproduction and mtDNA damage are causally related to age-related vascular dysfunction in humans (Csiszar et al. 2009; Mikhed et al. 2015). Although we have not analyzed DNA damage and AIM2 response here, this suggests that
AIM2-mediated DNA surveillance might be important for VSMC function and AAA formation, as well. It is tempting to speculate that oxidative stress, resulting in mitochondrial damage and mtDNA release into the cytoplasm of VSMC, might be detected by AIM2, which is necessary for DNA damage response. Deletion or mutation of AIM2 might therefore result in increased DNA-damage-induced VSMC senescence and/or osteoblast-like differentiation. Interestingly, and according to our animal experiments, this in turn resulted in a lower responsiveness to AngII and thus a lower AA incidence than in WT mice. It should be noted here, that the most commonly used WT mouse strain $\mathrm{C} 57 \mathrm{Bl} / 6 \mathrm{~J}$ and the mutated Aim2-/- strain are both affected by deficiency of mitochondrial Nicotinamide $\mathrm{Nu}$ cleotide Transhydrogenase (NNT), a core protein in the mitochondrial respiratory chain, resulting in redox abnormalities, which are not present in the $\mathrm{C} 57 \mathrm{Bl} / 6 \mathrm{~N}$ WT mouse strain (Simon et al. 2013). In a recent study, that was performed in parallel to the experiments presented here, we could show that the $\mathrm{C} 57 \mathrm{Bl} / 6 \mathrm{~J}$, NNT deficient mouse strain is particularly susceptible to AngII-induced aneurysm formation, and VSMC derived from C57BL/6 J mice display increased oxidative stress and DNA damage (Wortmann et al., unpublished data). Potentially, Aim2 deficiency in the NNT deficient background might result in different phenotypic changes of VSMC that in NNTproficient murine and human VSMC. Alternatively, the protective effect of Aim2 deficiency on AA formation that was observed here, is based on macrophages, which have not been investigated in this study. It will thus be important to further study AIM2 and its role in different cell types during AA formation in both, mice and humans.

Regardless of the mechanism, our findings are in line with recent studies demonstrating that inflammasome activation leads to the development of AngII-induced aortic aneurysm in hypercholesterolaemic (Apoe-/-) mice (Usui et al. 2015). According to this previous study, AA was formed in 10/14 ( 71\%) of Apoe-/- mice, whereas only $2 / 8$ (25\%) of Apoe-/-Nlrp3-/- mice and 4/14 ( 29\%) Apoe-/- Casp 1-/- mice developed an AA after AngII infusion. Using WT instead of Apoe-/- mice as a background, we here found AAs in $13 / 17$ (76\%) of WT mice, but only in 15/31 (48\%) of Aim2-/- mice. AIM2 may thus be added to the list of inflammasome components, interfering with AA formation, although the extent of this interference appears to be weaker for AIM2 than for NLRP3 or Caspase-1. Whether the here observed effects of Aim2-deletion will be stronger pronounced on the background of Apoe-/- mice, is currently under investigation.

Increasing evidence suggests that the innate immune system and in particular inflammasomes, are major contributors to cardiovascular disease, including AA formation (Dihlmann et al. 2014; Johnston et al. 2013, 2014; Li et al. 2014; 
Wortmann et al. 2019a, b). However, it is unclear so far, how the innate immune system contributes to AA formation and which cell types are the major players in disease progression. Inflammasome activation has been suggested to be involved in VSMC phenotype transition during vascular remodeling (Gardner et al. 2015; Ren et al. 2017; Sun et al. 2017; Wen et al. 2013; Wu et al. 2017). Whereas these studies focused predominantly on the NLRP3 inflammasome, we here present evidence for a role of AIM2 in regulating the VSMC response to AA-inducing mechanisms. According to our data, Aim2 deletion resulted in reduced inflammatory response of VSMC from control animals. However, Aim2 deletion did not affect inflammatory cell infiltration of AAs after 28 days of continuous AngII infusion. Aim2 deficiency might thus exert different impact on VSMC and myeloid cells. As mentioned above, we cannot exclude that the protective effect of AIM2 might be independent from reducing the inflammatory response of VSMC, i.e. resulting from some so far unknown mechanism. No robust differences in elastin breaks or its organization were apparent in histological samples. Because of the limited number of histologically analyzable aneurysm samples, we did not examine Mmp expression in histological samples for statistical analysis. Given that $M m p 9$ mRNA expression in VSMC was not associated with the genotype, we assume that elastin degradation is not affected by Aim2-/- deletion.

Analysis of calcification-associated mRNA expression suggested that Aim2 deletion results in persistent induction of Bmp4 and repression of Tnfsf11/Rankl in murine VSMC. BMP4 is a member of the bone morphogenetic protein family and a marker for osteochondrogenic differentiation in bone, and other tissues (Carreira et al. 2014). In contrast, Tnfsf11/Rankl is considered an osteoclast differentiation factor, (Karsenty 1999). Recently, it was demonstrated that human and murine aneurysms express high levels of Tnfsf11/Rankl and are more closely associated with the osteoclast-like catabolic degradation of the aorta than with the osteoblast-like anabolic processes of arterial calcification (Kelly et al. 2019; Takei et al. 2016). In addition, RANKL was shown to mediate osteoclastogenic differentiation of macrophages in the abdominal aorta of AngII-infused Apoe deficient mice (Tanaka et al. 2018). Correspondingly, the data presented here suggest that Aim 2 deficiency might trigger VSMC to a more osteoblast-like phenotype transition by reducing expression of Tnfsf11/Rankl and inducing expression of Bmp4. Conversely, Aim2 expression in WT VSMC, i.e. in response to cytosolic DNA, appears to allow for an osteoclast-like differentiation of VSMC, thereby promoting catabolic degradation. Thus, shifting of VSMC to a phenotype predisposed for anabolic calcification, with increased senescence and reduced proliferation does not necessarily weaken the aortic wall. This conclusion is further supported by previous studies demonstrating that vessels with greater calcification exhibit reduced aneurysm growth and the areas of aneurysmal vessels with less calcification may be the most likely sites of rupture (Lindholt 2008; Nakayama et al. 2016; Raghavan et al. 2006). In line with the reduced Rankl/sRANKL levels, expression of the osteogenic transcription factor Runx2 was reduced in aging and calcifying Aim2-/VSMC compared with WT VSMC. RUNX2 has been demonstrated to directly bind to and control the Rankl promoter, thereby regulating its expression (Byon et al. 2011). It should be noted here, that the decrease of an osteoclast marker does not necessarily provide evidence for osteogenic differentiation or the lack thereof. It was demonstrated that calcification may likewise occur without osteogenic differentiation (O'Neill and Adams 2014). Moreover, our study is limited by lacking analysis of additional osteogenic differentiation markers such as osteocalcin, osteopontin, osteoportegerin, bone sialoprotein, or MGP. Thus, the precise role of AIM2 in regulating osteogenic signaling in VSMC remains to be determined.

Table 1 Effects of Aim2 expression/knockout on VSMC differentiation and aortic remodeling

\begin{tabular}{lll}
\hline VSMC Genotype & Aim2 -/- & WT \\
\hline RankI/Tnfff11 expression & low & high \\
Bmp4 expression & high & low \\
$\begin{array}{l}\text { Calcification in mineralization medium } \\
\text { (OM) }\end{array}$ & high & low \\
Osteochondrogenic differentiation & Osteoblast-like & Osteoclast-like \\
Role in AAA & Anabolic calcification; reduced incidence of aortic & Catabolic degradation; high incidence of aortic \\
& dilation & dilation \\
NIrp3 expression & low & high \\
II16 expression & low & high \\
NF-kB (p65) activity & low & high \\
II-6 release & low & high \\
Inflammatory response & low & high \\
\hline
\end{tabular}




\section{Conclusion}

In summary, our data demonstrate that AIM2 affects several molecular mechanisms involved in aortic remodeling and murine AA formation. The signaling pathways resulting in reduced proliferation and increased senescence of Aim2 deficient VSMC remain to be investigated. The mechanism resulting in increased calcification of Aim 2 deficient VSMC has been elucidated in part. Based on our data, we suggest the following model (Table 1): In Aim2deficient VSMC, the absence of the osteoclast differentiation factor Tnfsf11/Rankl, paralleled by high Bmp4 levels, triggers the cells to differentiate into osteoblast-like cells with a low inflammatory response. In contrast, WT VSMC, expressing high Tnfsf11/Rankl and low Bmp4 levels differentiate into osteoclast-like VSMC with a high inflammatory response. Whether AIM2 deficiency results in similar VSMC phenotype transitions in human AAA, and whether this is associated with AAA pathophysiology, needs to be investigated, i.e. by studying AIM2 mutations/ expression particularly in calcified versus non-calcified AAA tissue samples.

\section{Supplementary information}

Supplementary information accompanies this paper at https://doi.org/10. 1186/s10020-020-00212-z.

Additional file 1: Supplementary table 1. primer sequences for realtime PCR. Supplementary figure S1. Mouse VSMC (C57BI/6 N) were grown for 27 days in Smooth muscle cell growth medium or in osteoblast mineralization medium. Subsequently calcification was visualized in both cultures by staining with Alizarin Red $\mathrm{S}$ as described in Materials and methods. Images were taken using a light microscope with phase contrast (a) or bright field (b). Supplementary figure S2. Analysis of mRNA expression by RT-qPCR. Total RNA was extracted from VSMC grown in vitro with normal growth medium (-OM) or osteoblast mineralization medium (+ OM). A.u. arbitrary unit; relative expression of target gene was normalized against expression of housekeeping genes (Actb, Gapdh and B2m). Bars show the mean $+/-$ SD of $n=3$ measurements of 3 VSMC pools, each. Data were statistically analyzed by oneway-ANOVA. ${ }^{*}: P<0.05 ;{ }^{* *}: P<0.01 ;{ }^{* * *}: P<0.0001$; ns: not significant. Supplementary figure $\mathbf{S 3}$. Expression of genes encoding inflammsome components. Analysis of mRNA expression of Asc (a), and Casp1 (b) by real-time reverse-transcriptase-polymerse chain reaction ( $n=3$ measurements of 3 experiments for each). Total RNA was extracted from VSMC grown in vitro with normal growth medium (-OM) or osteoblast mineralization medium (+ OM). A.u. arbitrary unit; relative expression of target gene was normalized against expression of housekeeping genes (Actb, Gapdh and B2m). Asc expression was similarly low in VSMC of both genotypes grown in normal growth medium. After shifting the cells to mineralization medium, Asc mRNA levels were significantly increased in both genotypes (-OM versus + OM: $P<0.001$ ), although the increase was less intense in Aim2-/- VSMC (a). In contrast, expression of Casp 1 was increased in Aim2-/- compared with WT VSMC in either growth medium (b). Data were statistically analyzed by one-way-ANOVA. ${ }^{*}: P<$ 0.05; **: $P<0.01$; ***: $P<0.0001$; ns: not significant. Supplementary figure S4. Plasma levels of inflammatory cytokines IL-1 $\beta$ (a) and IL-6 (b) were determined by specific ELISAs from Angll-treated WT BI6J and Aim2 deficient mice at the end of the 28d infusion. Data show the mean and standard deviations of $n=11$ mice for each group. c. Real-time RT-PCR of aortas showing $\|1 b\| 6,, \| 18$ and Mcp1 gene expression of Angll-infused WT Bl6J $(n=3)$ and Angll-infused Aim2-/- $(n=3)$ mice. Data show the mean $+/$ - SEM of three mice analyzed in triplicates. n.s.: not significant Supplementary figure S5. a. Protein Expression of the senescence marker p16ink4A is increased in AA. Mouse aortas with and without aneurysms (AAA) were lysed and analyzed by Western blotting. b. Quantitative analysis of p16ink4A expression normalized to Vinculin. Blots were scanned and signals were densitometrically analyzed by Image J software. c. Mouse VSMC (C57BI/6 J) were isolated from Angll treated mice and grown in vitro. Each pool contained VSMC of 3 animals. VSMC derived from Aim2-/- mice are larger, rounded and contain big vacuoles. The picture shows representative cultures of passage 3 from $n=3$ (Aim2-/-) and $n=3$ (WT) VSMC pools. d. mRNA levels of VSMC derived from Angll infused WT Bl6J ( $n=3$ pools) and Aim2-/- ( $n=3$ pools) animals.). A.u. arbitrary unit; relative expression of target gene was normalized against expression of housekeeping genes (Actb, Gapdh and B2m).

\section{Abbreviations}

AA: Aortic aneurysm; AAA: Abdominal aortic aneurysm; ACTB: Actin B; AIM2: Absent in Melanoma 2; Angll: Angiotensin II; APC: Apoptosisassociated speck-like protein containing a caspase recruitment domain; Apoe: Apolipoprotein E; ARS: Alizarin Red S; aSMA: Alpha-smooth muscle actin; B2M: Beta-2-microglobulin; BMP: Bone morphogenic protein; CASP1: Caspase-1; CDKN2A: Cyclin dependent kinase inhibitor 2A; ECL: Enhanced chemoluminescence; GAPDH: Glyceraldehyde-3-phosphate dehydrogenase; IL: Interleukin; MCP1: Monocyte chemoattractant protein 1; NLRP3: NLR family pyrin domain containing 3; PBS: Phosphate buffered saline; qRT-PCR: Quantitative reverse transcription polymerase chain reaction; RANKL: Receptor Activator of NF-kB (nuclear factor 'kappa-light-chain-enhancer' of activated B-cells) ligand; RUNX2: Runt-related transcription factor 2; SOX9: SRY-related HMG-(high mobility group) box gene 9; TNFSF11: Tumor necrosis factor superfamily member 11; VSMC: Vascular smooth muscle cell; WT: Wild type

\section{Acknowledgements}

We thank Anja Spieler for excellent technical assistance in conducting immunohistochemical staining of mouse tissues, cell culture experiments and acquisition of secondary data from these experiments. We thank Prof. Dr. Niels Grabe (Tissue Imaging and Analysis Center, Bioquant, University of Heidelberg) for scanning histological samples for digital imaging.

\section{Authors' contributions}

MW designed and performed the animal experiments regarding implantation of osmotic pumps and isolation of VSMC. MA performed VSMC culturing in vitro and some of the Western blots. MH was involved in experimental design and manuscript editing. SD designed the cell culture experiments, analyzed and interpreted the cell culture data (mRNA expression, protein expression, cytokine release, calcification), and was a major contributor in writing the manuscript. All authors read and approved the final manuscript.

\section{Funding}

This study was supported by grants from Deutsche Forschungsgemeinschaft (DFG) to SD and MW (Project number 323488362) and from Stiftung Chirurgie Heidelberg to MW (Project number 2016/39).

Open access funding provided by Projekt DEAL.

\section{Availability of data and materials}

All relevant data supporting the conclusions of this article is included within the article and its additional files. Original raw data of real-time RT-PCR and original colorimetric data from the ELISAs are available upon request.

\section{Ethics approval and consent to participate}

The study does not use any human data or material. Therefore, ethical approval is not applicable.

All animal experiments in this study were performed in accordance with federal law for animal protection and approved by the regional council of Baden-Wuerttemberg (Regierungspraesidium Karlsruhe).

\section{Consent for publication}

Not applicable.

\section{Competing interests}

The authors declare that they have no competing interests. 


\section{Author details}

1 Department of Vascular and Endovascular Surgery, University Hospital Heidelberg, University of Heidelberg, Im Neuenheimer Feld 110, 69120 Heidelberg, Germany. ${ }^{2}$ Present Address: Department of Vascular Surgery, Luzerner Kantonsspital, Spitalstrasse, 6000 Luzern 16, Switzerland.

Received: 13 May 2020 Accepted: 24 August 2020

Published online: 15 September 2020

\section{References}

Ailawadi G, Moehle CW, Pei H, Walton SP, Yang Z, Kron IL, Lau CL, Owens GK. Smooth muscle phenotypic modulation is an early event in aortic aneurysms. J Thorac Cardiovasc Surg. 2009;138:1392-9.

Bae JH, Jo SI, Kim SJ, Lee JM, Jeong JH, Kang JS, Cho NJ, Kim SS, Lee EY, Moon JS. Circulating cell-free mtDNA contributes to AIM2 Inflammasome-mediated chronic inflammation in patients with type 2 diabetes. Cells. 2019;8(4):328.

Bennett MR, Sinha S, Owens GK. Vascular smooth muscle cells in atherosclerosis. Circ Res. 2016;118:692-702.

Briard B, Place DE, Kanneganti TD. DNA sensing in the innate immune response. Physiology (Bethesda). 2020;35:112-24.

Byon CH, Sun Y, Chen J, Yuan K, Mao X, Heath JM, Anderson PG, Tintut Y, Demer $\mathrm{LL}$, Wang $\mathrm{D}$, Chen Y. Runx2-upregulated receptor activator of nuclear factor kappaB ligand in calcifying smooth muscle cells promotes migration and osteoclastic differentiation of macrophages. Arterioscler Thromb Vasc Biol. 2011;31:1387-96

Carreira AC, Alves GG, Zambuzzi WF, Sogayar MC, Granjeiro JM. Bone morphogenetic proteins: structure, biological function and therapeutic applications. Arch Biochem Biophys. 2014;561:64-73.

Csiszar A, Podlutsky A, Wolin MS, Losonczy G, Pacher P, Ungvari Z. Oxidative stress and accelerated vascular aging: implications for cigarette smoking. Front Biosci (Landmark Ed). 2009;14:3128-44

Daugherty A, Manning MW, Cassis LA. Angiotensin II promotes atherosclerotic lesions and aneurysms in apolipoprotein E-deficient mice. J Clin Invest. 2000; 105:1605-12.

Dihlmann S, Erhart P, Mehrabi A, Nickkholgh A, Lasitschka F, Bockler D, Hakimi M. Increased expression and activation of absent in melanoma 2 inflammasome components in lymphocytic infiltrates of abdominal aortic aneurysms. Mol Med. 2014;20:230-7.

Fernandes-Alnemri T, Yu JW, Datta P, Wu J, Alnemri ES. AlM2 activates the inflammasome and cell death in response to cytoplasmic DNA. Nature. 2009; 458:509-13.

Forsdahl SH, Singh K, Solberg S, Jacobsen BK. Risk factors for abdominal aortic aneurysms: a 7-year prospective study: the Tromso study, 1994-2001. Circulation. 2009;119:2202-8

Freise C, Kretzschmar N, Querfeld U. Wnt signaling contributes to vascular calcification by induction of matrix metalloproteinases. BMC Cardiovasc Disord. 2016;16:185

Gardner SE, Humphry M, Bennett MR, Clarke MC. Senescent vascular smooth muscle cells drive inflammation through an interleukin-1alpha-dependent senescence-associated secretory phenotype. Arterioscler Thromb Vasc Biol. 2015;35:1963-74

Golledge J. Abdominal aortic aneurysm: update on pathogenesis and medical treatments. Nat Rev Cardiol. 2019;16:225-42.

Hakimi M, Peters A, Becker A, Bockler D, Dihlmann S. Inflammation-related induction of absent in melanoma 2 (AIM2) in vascular cells and atherosclerotic lesions suggests a role in vascular pathogenesis. J Vasc Surg. 2014;59:794-803.e792

Hannawa KK, Eliason JL, Upchurch GR Jr. Gender differences in abdominal aortic aneurysms. Vascular. 2009;17(Suppl 1):S30-9.

Hornung V, Ablasser A, Charrel-Dennis M, Bauernfeind F, Horvath G, Caffrey DR, Latz E, Fitzgerald KA. AIM2 recognizes cytosolic dsDNA and forms a caspase1-activating inflammasome with ASC. Nature. 2009;458:514-8.

Hortells L, Sur S, St Hilaire C. Cell phenotype transitions in cardiovascular calcification. Front Cardiovasc Med. 2018;5:27

Johnston WF, Salmon M, Pope NH, Meher A, Su G, Stone ML, Lu G, Owens GK, Upchurch GR Jr, Ailawadi G. Inhibition of interleukin-1 beta decreases aneurysm formation and progression in a novel model of thoracic aortic aneurysms. Circulation. 2014;130:S51-9.

Johnston WF, Salmon M, Su G, Lu G, Stone ML, Zhao Y, Owens GK, Upchurch GR Jr, Ailawadi G. Genetic and pharmacologic disruption of interleukin-1beta signaling inhibits experimental aortic aneurysm formation. Arterioscler Thromb Vasc Biol. 2013;33:294-304.

Karsenty G. The genetic transformation of bone biology. Genes Dev. 1999;13: 3037-51.

Kelly MJ, Igari K, Yamanouchi D. Osteoclast-like cells in aneurysmal disease exhibit an enhanced proteolytic phenotype. Int J Mol Sci. 2019;20(19):4689.

Krishna SM, Seto SW, Jose RJ, Li J, Morton SK, Biros E, Wang Y, Nsengiyumva V, Lindeman JH, Loots GG, et al. Wnt signaling pathway inhibitor Sclerostin inhibits angiotensin II-induced aortic aneurysm and atherosclerosis. Arterioscler Thromb Vasc Biol. 2017;37:553-66.

Lammert CR, Frost EL, Bellinger CE, Bolte AC, McKee CA, Hurt ME, Paysour MJ, Ennerfelt HE, Lukens JR. AIM2 inflammasome surveillance of DNA damage shapes neurodevelopment. Nature. 2020;580:647-52.

Li X, Deroide N, Mallat Z. The role of the inflammasome in cardiovascular diseases. J Mol Med (Berl). 2014;92:307-19.

Lindholt JS. Aneurysmal wall calcification predicts natural history of small abdominal aortic aneurysms. Atherosclerosis. 2008;197:673-8.

Mikhed Y, Daiber A, Steven S. Mitochondrial oxidative stress, mitochondrial DNA damage and their role in age-related vascular dysfunction. Int J Mol Sci. 2015;16:15918-53.

Moriyama M, Nagai M, Maruzuru Y, Koshiba T, Kawaguchi Y, Ichinohe T. Influenza virus-induced oxidized DNA activates inflammasomes. iscience. 2020;23: 101270.

Nakayama A, Morita H, Hayashi N, Nomura Y, Hoshina K, Shigematsu K, Ohtsu H, Miyata T, Komuro I. Inverse correlation between calcium accumulation and the expansion rate of abdominal aortic aneurysms. Circ J. 2016;80:332-9.

O'Neill WC, Adams AL. Breast arterial calcification in chronic kidney disease: absence of smooth muscle apoptosis and osteogenic transdifferentiation. Kidney Int. 2014;85:668-76.

Owens GK, Kumar MS, Wamhoff BR. Molecular regulation of vascular smooth muscle cell differentiation in development and disease. Physiol Rev. 2004;84: 767-801.

Petsophonsakul P, Furmanik M, Forsythe R, Dweck M, Schurink GW, Natour E, Reutelingsperger C, Jacobs M, Mees B, Schurgers L. Role of vascular smooth muscle cell phenotypic switching and calcification in aortic aneurysm formation. Arterioscler Thromb Vasc Biol. 2019;39:1351-68.

Qi M, Dai D, Liu J, Li Z, Liang P, Wang Y, Cheng L, Zhan Y, An Z, Song Y, et al AIM2 promotes the development of non-small cell lung cancer by modulating mitochondrial dynamics. Oncogene. 2020;39:2707-23.

Raghavan ML, Kratzberg J, Castro de Tolosa EM, Hanaoka MM, Walker P, da Silva ES. Regional distribution of wall thickness and failure properties of human abdominal aortic aneurysm. J Biomech. 2006;39:3010-6.

Reimerink JJ, van der Laan MJ, Koelemay MJ, Balm R, Legemate DA. Systematic review and meta-analysis of population-based mortality from ruptured abdominal aortic aneurysm. Br J Surg. 2013;100:1405-13.

Ren XS, Tong Y, Ling L, Chen D, Sun HJ, Zhou H, Qi XH, Chen Q, Li YH, Kang YM, Zhu GQ. NLRP3 gene deletion attenuates angiotensin II-induced phenotypic transformation of vascular smooth muscle cells and vascular remodeling. Cell Physiol Biochem. 2017:44:2269-80.

Riches K, Clark E, Helliwell RJ, Angelini TG, Hemmings KE, Bailey MA, Bridge $\mathrm{Kl}$, Scott DJA, Porter KE. Progressive development of aberrant smooth muscle cell phenotype in abdominal aortic aneurysm disease. J Vasc Res. 2018;55:35-46.

Sampson UK, Norman PE, Fowkes FG, Aboyans V, Yanna S, Harrell FE Jr, Forouzanfar MH, Naghavi M, Denenberg JO, McDermott MM, et al. Global and regional burden of aortic dissection and aneurysms: mortality trends in 21 world regions, 1990 to 2010. Glob Heart. 2014;9:171-180. e110.

Sharma BR, Karki R, Kanneganti TD. Role of AIM2 inflammasome in inflammatory diseases, cancer and infection. Eur J Immunol. 2019:49(11):1998-2011.

Simon MM, Greenaway S, White JK, Fuchs H, Gailus-Durner V, Wells S, Sorg T,

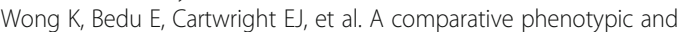
genomic analysis of $\mathrm{C} 57 \mathrm{BL} / 6 \mathrm{~J}$ and $\mathrm{C} 57 \mathrm{BL} / 6 \mathrm{~N}$ mouse strains. Genome Biol. 2013;14:R82.

Sun HJ, Ren XS, Xiong XQ, Chen YZ, Zhao MX, Wang JJ, Zhou YB, Han Y, Chen Q, $\mathrm{Li} Y \mathrm{YH}$, et al. NLRP3 inflammasome activation contributes to VSMC phenotypic transformation and proliferation in hypertension. Cell Death Dis. 2017;8: e3074.

Takei Y, Tanaka T, Kent KC, Yamanouchi D. Osteoclastogenic differentiation of macrophages in the development of abdominal aortic aneurysms. Arterioscler Thromb Vasc Biol. 2016;36:1962-71. 
Tanaka T, Kelly M, Takei Y, Yamanouchi D. RANKL-mediated osteoclastogenic differentiation of macrophages in the abdominal aorta of angiotensin IIinfused apolipoprotein E knockout mice. J Vasc Surg. 2018;68:48S-59S.e41.

Tang Z, Wang A, Yuan F, Yan Z, Liu B, Chu JS, Helms JA, Li S. Differentiation of multipotent vascular stem cells contributes to vascular diseases. Nat Commun. 2012;3:875

Towler DA. "Osteotropic" Wnt/LRP signals: high-wire artists in a balancing act regulating aortic structure and function. Arterioscler Thromb Vasc Biol. 2017; 37:392-5.

Usui F, Shirasuna K, Kimura H, Tatsumi K, Kawashima A, Karasawa T, Yoshimura K, Aoki H, Tsutsui H, Noda T, et al. Inflammasome activation by mitochondrial oxidative stress in macrophages leads to the development of angiotensin II-induced aortic aneurysm. Arterioscler Thromb Vasc Biol. 2015;35:127-36.

Wen C, Yang X, Yan Z, Zhao M, Yue X, Cheng X, Zheng Z, Guan K, Dou J, Xu T, et al. Nalp3 inflammasome is activated and required for vascular smooth muscle cell calcification. Int J Cardiol. 2013;168:2242-7.

Wortmann M, Skorubskaya E, Peters AS, Hakimi M, Bockler D, Dihlmann S. Necrotic cell debris induces a NF-kappaB-driven inflammasome response in vascular smooth muscle cells derived from abdominal aortic aneurysms (AAA-SMC). Biochem Biophys Res Commun. 2019a;511:343-9.

Wortmann M, Xiao X, Wabnitz G, Samstag Y, Hakimi M, Bockler D, Dihlmann S. AIM2 levels and DNA-triggered inflammasome response are increased in peripheral leukocytes of patients with abdominal aortic aneurysm. Inflamm Res. 2019b;68:337-45.

Wu D, Ren P, Zheng Y, Zhang L, Xu G, Xie W, Lloyd EE, Zhang S, Zhang $\mathrm{O}$ Curci JA, et al. NLRP3 (nucleotide oligomerization domain-like receptor family, pyrin domain containing 3)-caspase-1 Inflammasome degrades contractile proteins: implications for aortic biomechanical dysfunction and aneurysm and dissection formation. Arterioscler Thromb Vasc Biol. 2017;37:694-706

Wu X, Cakmak S, Wortmann M, Hakimi M, Zhang J, Bockler D, Dihlmann S. Sexand disease-specific inflammasome signatures in circulating blood leukocytes of patients with abdominal aortic aneurysm. Mol Med. 2016;22:508-18.

Wu X, Hakimi M, Wortmann M, Zhang J, Bockler D, Dihlmann S. Gene expression of inflammasome components in peripheral blood mononuclear cells (PBMC) of vascular patients increases with age. Immun Ageing. 2015;12:15.

\section{Publisher's Note}

Springer Nature remains neutral with regard to jurisdictional claims in published maps and institutional affiliations.

Ready to submit your research? Choose BMC and benefit from:

- fast, convenient online submission

- thorough peer review by experienced researchers in your field

- rapid publication on acceptance

- support for research data, including large and complex data types

- gold Open Access which fosters wider collaboration and increased citations

- maximum visibility for your research: over $100 \mathrm{M}$ website views per year

At $\mathrm{BMC}$, research is always in progress.

Learn more biomedcentral.com/submissions 